\title{
Docosahexaenoic Acid Serving As Sensitizing Agents And Gefitinib Resistance Revertants In EGFR Targeting Treatment
}

This article was published in the following Dove Press journal: OncoTargets and Therapy

\author{
Xuansheng Ding* \\ Lei Ge* \\ Aiwen Yan \\ Yuyin Ding \\ Junye Tao \\ Qianqian Liu \\ Chen Qiao*
}

Department of Basic Medicine and Clinical Pharmacy, China Pharmaceutical University, Nanjing 21 I 198, People's Republic of China

*These authors contributed equally to this work
Correspondence: Chen Qiao

Department of Basic Medicine and

Clinical Pharmacy, China Pharmaceutical

University, No. 639 Longmian Road,

Jiangning District, Nanjing, Jiangsu,

People's Republic of China

Tel +8613913807716

Email 279201754@qq.com
Objective: Due to the resistance of cancer cells, chemotherapy has been severely restricted. Docosahexaenoic acid (DHA) has been broadly identified as the chemo-sensitizing agent and revertant of multidrug resistance owing to its pleiotropic characteristics; however, it has not been well interpreted. The purpose of this research was to identify the anticancer role of DHA and its combination with the chemotherapeutic agent Gefitinib in non-small cell lung cancer (NSCLC). Methods: Human chemo-sensitive NSCLC PC-9 cells and the Gefitinib-resistant counterpart PC-9/GR cells were adopted to assess the effects of the integrated DHA and Gefitinib treatments in vitro and vivo, for which the combination index $(\mathrm{CI})$, apoptosis rate and the epithelial growth factor receptor (EGFR) pathway were analyzed.

Results: Comparing with the control cells, the DHA-treated PC-9/GR cells triggered the increase of drug absorption and sensitivity, suggesting that the sensitivity of chemotherapeutic drug could be induced by DHA. Moreover, the elevation of phosphorylation levels of EGFR and the downstream extracellular signal-regulated kinase (ERK) in the cellular lysates were induced by the DHA+Gefitinib treatment. Additionally, the long-term Gefitinib stimulated PC-9 model revealed that DHA could revert the Gefitinib resistance.

Conclusion: This is the first research that indicated the novel biochemical effect of DHA, which can help in overcoming the resistance of EGFR-TKI in NSCLC cells and broaden the horizon of the DHA supplementation during the NSCLC therapy.

Keywords: non-small cell lung cancer, drug resistance, DHA

\section{Introduction}

Lung cancer has been one of the primary causes of cancer mortality worldwide. Especially, non-small cell lung cancer (NSCLC) accounts for over $70 \%$ of the patients suffered from lung cancer. ${ }^{1}$ The epidermal growth factor receptor (EGFR) mutant has been reported to be observed in $30-50 \%$ of the NSCLC patients, which motivated the tumor growth and proliferation. ${ }^{2}$ Overexpression or mutation in the intracellular EGFR has been verified to be existed in approximately $60 \%$ of the cases, implying that it was associated with the pathogenesis of NSCLC. Cell proliferation or anti-apoptosis could be induced by the mutations, even without the extracellular epidermal growth factor (EGF). There were conformational changes in the functionalized ERFR and phosphorylated intracellular domain, rendering the downstream signal transduction in a variety of pathways, including the PI3K and ERK signaling pathways. ${ }^{3}$ In the terminal NSCLC cases, the therapy based on the epidermal growth factor receptor-tyrosine kinase inhibitors (EGFR-TKIs) has made a remarkable breakthrough. After 1 year of treatment, some 
subjects exhibited the EGFR-TKIs resistance which limited the clinical application of these drugs, and the molecular mechanism was still unclearly interpreted.

Various epidemiological studies have emphasized the relationships between omega-3 fatty acids (FAs) and incidences of cancers, such as breast, renal, prostate, liver and pancreas cancers. ${ }^{4-6}$ Additionally, the FAs have been proved to elevate the efficacy of chemotherapy. ${ }^{7}$ In recent years, in the random controlled clinical assays, the supplementation of docosahexaenoic acid (DHA) with the chemotherapies could effectively relieve the conditions. ${ }^{8}$ Murphy et al have reported that the therapy response rate and clinical benefit were found to be increased twice in the treatment of DHA supplement for the NSCLC patients with platinum-based chemotherapy in comparison with the subjects without supplement. ${ }^{9}$ Previous researches have also illustrated that the supplement of DHA with the chemotherapy based on anthracyclin against the metastatic breast cancer effectively alleviated the symptoms, which demonstrated that DHA may serve as a promising adjuvant for cancer treatment. ${ }^{10}$ In this research, the anti-tumor role of DHA in combination with EGFR-TKIs was investigated and the relevant mechanism was also discussed. Two human lung cancer cell lines, PC-9 and PC-9/GR (Gefitinib-resistant), have been applied to evaluate the in vitro effect of DHA in sensitivity to Gefitinib. In addition, the combination index (CI) and apoptosis rate were calculated to evaluate the efficacy of the combinative treatment of DHA and Gefitinib. Additionally, a fluorescent-labeled probe with a quinazoline structure was utilized to estimate the absorption of Gefitinib supplying with DHA. The long-term PC-9 cell model treated with Gefitinib was adopted to identify whether DHA exerted the Gefitinib resistance revertant effects through the EGFR pathway.

\section{Materials And Methods Materials And Cell Culture}

Human non-small cell lung cancer PC-9 and PC-9/GR were donated by Dr. Zhou Caicun (Shanghai Pulmonary Hospital, Shanghai, China), which were cultivated in Dulbecco's Modified Eagle Medium (DMEM) (Gibco TM, 11965092) with $10 \%$ fetal bovine serum (FBS, Biological Industries, 04001-1A-US), $100 \mathrm{U} / \mathrm{mL}$ penicillin, and $100 \mathrm{mg} / \mathrm{mL}$ streptomycin (Gibco TM, $15140-122$ ) at $37^{\circ} \mathrm{C}$ in the atmosphere of $5 \% \quad \mathrm{CO}_{2}$. The gifted cells were approved by China Pharmaceutical University ethics committee. Gefitinib was generously obtained from AstraZeneca China. DHA (D2534$1 \mathrm{G})$, methyl- $\beta$-cyclodextrin (MBCD) (C4555-1G), and cholesterol (C3045-5G) were purchased from Sigma-Aldrich.
Doxorubicin $\left(\mathrm{C}_{27} \mathrm{H}_{29} \mathrm{O}_{11} \mathrm{~N} \cdot \mathrm{HCl}\right)$ was obtained from Pfizer Italia S.r.l dissolved in normal saline. Cell Counting Kit-8 (KGA317s-500) was bought from KeyGen (Nanjing, China). The skeleton of Gefitinib quinazoline labeled by fluorescent was kindly donated by Dr. Wang Fuyi (Institute of Chemistry, Chinese Academy of Sciences, Beijing, China).

\section{Cell Viability}

To evaluate the sensitivity of EGFR-TKI in tumor cells, cell viability was analyzed based on the CCK- 8 assay. Cells at the logarithmic phase were collected and seeded to 96 -well plates with a density of $5 \times 10^{3}$ cells per well with a volume of 100 $\mu \mathrm{L}$, which were further cultivated overnight. After the attachment, a series of concentrations of DHA and Gefitinib were added, which were incubated for another $24 \mathrm{hrs}$. Afterwards, $10 \mu \mathrm{L}$ of CCK- 8 was added to each well followed by incubating for an additional $4 \mathrm{hrs}$ at $37^{\circ} \mathrm{C}$. The absorbance was detected by the microplate reader (Thermo Multiskan_FC, American) with $570 \mathrm{~nm}$ as the referenced wavelength. The results were represented as the inhibition rate of cells compared to the normal controls which showed in the form of mean \pm standard error of the mean (S.E.M) ( $n=6$ for each group). CI was calculated based on the previous study (Chou, 2006) ${ }^{11}$ by Calcusyn 2.0 software.

\section{Animal Model}

Forty male athymic BALB/c nude mice (35-40 days old, 18-22 g) were purchased from the Experimental Animal Center of Zhejiang Province (Hangzhou, China). The animals were housed at ambient temperature $\left(25 \pm 5{ }^{\circ} \mathrm{C}\right)$ and $45 \pm 5 \%$ relative humidity with a 12-hr light/dark cycle (lights on from 6:00 a.m. to 6:00 p.m.), a standard diet contained $20 \% \mathrm{w} / \mathrm{w}$ fat and free access to water. After 1-week acclimatization, twenty nude mice were inoculated subcutaneously with $1 \times 10^{7}$ PC-9 cells into the right axilla, and the other twenty nude mice were inoculated with $1 \times 10^{7} \mathrm{PC}-9 / \mathrm{GR}$ cells. After 12 days of growth, tumor size was measured using micrometer calipers. Mice that were inoculated with PC-9 cells or PC-9/GR cells that had similar tumor volumes were randomly divided into the following three groups (six mice/group): saline control, Gefitinib, Gefitinib+DHA. Gefitinib was dissolved at a concentration of $6.5 \mathrm{mg} / \mathrm{kg}$ in $1 \%$ DMSO and administered once a day by gavage. For the DHA groups, the diet was achieved by blending oils to obtain a DHA content of 3.9\% $\mathrm{w} / \mathrm{w}$ of total fat, which has been proven to enhance the docetaxel effect in breast cancer xenografts model. ${ }^{12}$ All experiments were performed in accordance with the Guide for Care 
and Use of Laboratory Animals of the Chinese National Institutes of Health.

\section{The Isolation Of Lipid Rafts And Analysis Of Cholesterol}

All the experiments were conducted on ice. The isolation of lipid rafts was completed using the UltraRIPA kit for Lipid Raft (F015) based on the instructions of the manufacturer. RIPA (KeyGen Biotech, KGP702-100) with $1 \mathrm{mM}$ PMSF (KeyGen Biotech, KGP610) and $1 \times$ cocktails (KeyGen Biotech, KGP602) were adopted for cell lysis and BCA protein analysis (Beyotime Biotechnology, P0010) was performed. Cholesterol was analyzed based on the Amplex ${ }^{\circledR}$ Red Cholesterol Assay Kit (Invitrogen, A12216) following the specifications. The incubation was maintained for 30 mins or longer at $37^{\circ} \mathrm{C}$, in the dark. Fluorescent analyses were performed using the fluorescence microplate reader (Thermo Fisher Scientific, Finland) with the excitation wavelength at $560 \mathrm{~nm}$ and detection wavelength at $590 \mathrm{~nm}$.

\section{Western Blot Assay}

Cells were harvested and lysed with $300 \mu \mathrm{L}$ ice-cold RIPA lysis buffer (KeyGen Biotech, KGP702-100) consisting of $1 \mathrm{mM}$ PMSF and protease inhibitor cocktail. The BCA Protein Assay Kit was adopted for the quantification of proteins in the lysate. Cell lysates consisting of $80 \mu \mathrm{g}$ protein were transferred to SDS-PAGE with $8-12 \%$ gradient polyacrylamide gels (Bis-Tris Midi Gel, Life Technologies, USA), which were detected based on immunoblotting with antibodies to the relevant proteins. Similarly, $\beta$-actin antibody (Servicebio, GB13001) served as the loading control. The primary antibodies were listed as follows, including Phospho-EGF Receptor (Tyr1068, D7A5) XP ${ }^{\circledR}$ Rabbit mAb (CST, \#3777), EGF Receptor (D38B1) XP Rabbit mAb (CST, \#4267), PhosphoAkt (Ser473) Antibody (CST, \#9271), Akt (pan) (C67E7) Rabbit mAb (CST, \#4691), Phospho-p44/42 MAPK (Erk1/2) (Thr202/Tyr204) (D13.14.4E) XP Rabbit mAb (CST, \#4370), and p44/42 MAPK (Erk1/2) (137F5) Rabbit mAb (CST, \#4695). Enhanced chemiluminescence was applied for the visualization of band results following the instructions (Hercules, CA, USA).

\section{Annexin V/PI Staining}

Apoptotic cells were determined according to the Annexin V-FITC Apoptosis Detection Kits (KeyGen, Nanjing, China) based on the instructions of the manufacturer. Briefly, $1 \times 10^{6}$ cells were collected, rinsed, and suspended in PBS. Cells were re-suspended with $500 \mathrm{~mL}$ binding buffer, followed by the addition of $5 \mathrm{~mL}$ AnnexinV-FITC and $5 \mathrm{~mL}$ PI was added. The death of apoptotic cells was identified by FACS Calibur flow cytometry (Becton Dickinson, San Jose, CA) promptly after the staining.

\section{Immuno-Cytochemical Assay}

Cells were washed with PBS and then fixed with 4\% paraformaldehyde in phosphate buffer ( $\mathrm{pH} 7.4)$ for 20 mins at room temperature. After rinsing with PBST and blocking with 3\% bovine serum albumin (BSA) in PBST for $1 \mathrm{hr}$, cells were treated with $10 \mu \mathrm{M}$ fluorescent probe with Gefitinib quinazoline for another $3 \mathrm{hrs}$. When staining for the nuclei, cells were rinsed with PBST and treated with DAPI for 15 mins. After rinsing by $\mathrm{PBS}$, cells were visualized by the laser scanning confocal microscope FV10-ASW (Ver 2.1, Olympus Corp, MPE FV1000) for the co-localized detection.

\section{Flow Cytometry}

PBS was applied to rinse the cells which were subsequently fixed with $4 \%$ paraformaldehyde in phosphate buffer ( $\mathrm{pH}$ 7.4) for 20 mins at room temperature. Rinsed with PBST and blocked with 3\% BSA in PBST for $1 \mathrm{hr}$, cells were then treated with $10 \mu \mathrm{M}$ fluorescent probe. Immediately, the fluorescent intensity was analyzed based on FACSCalibur flow cytometry (Becton Dickinson, San Jose, CA) with $488 \mathrm{~nm}$ as the excitation wavelength and $525 \mathrm{~nm}$ as the emission wavelength.

\section{Statistical Analysis}

The results were the representatives of three independent experiments, which were represented as mean \pm S.E.M. Prism 6.0 statistical software was utilized for the analyses. The two-tailed Student's $t$-test was applied to identify the significance. The variables with $p<0.05$ were considered as statistical significance.

\section{Results \\ DHA-Induced Apoptosis Of PC-9 And PC-9/GR Cells}

To evaluate the anti-tumor effect of DHA on NSCLC cells, PC-9 cells and the Gefitinib-resistant counterpart PC-9/GR cells were selected for the present study. Firstly, the CCK-8 assay and Annexin V/PI staining assay were performed in PC-9 cells and PC-9/GR cells. Figure 1A-C revealed that PC-9/GR exhibited more drug resistibility than PC-9 after the Gefitinib treatment, and Figure 1D-F indicated that the IC50 
A

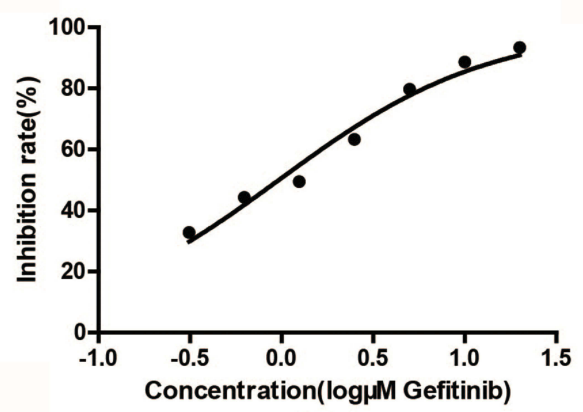

D

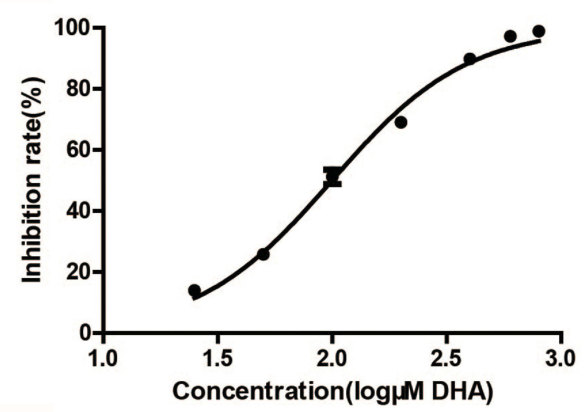

B

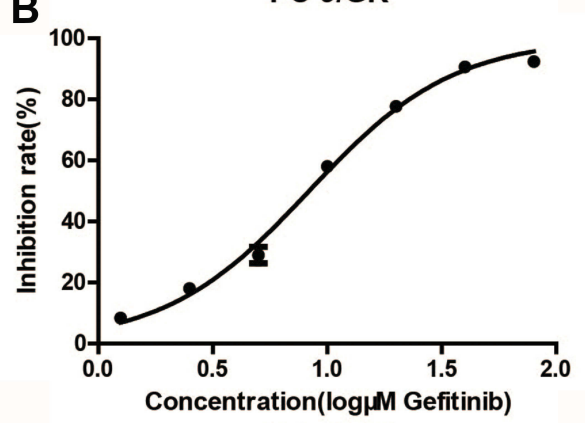

E

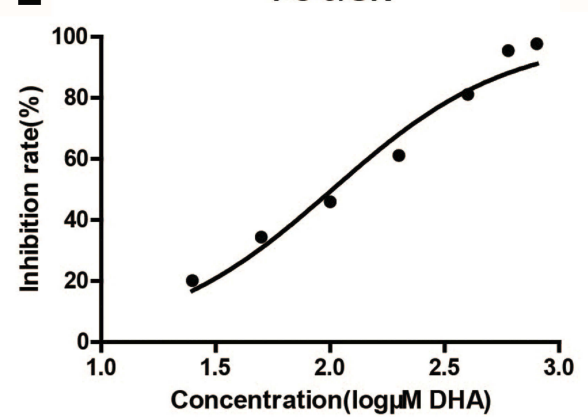

C
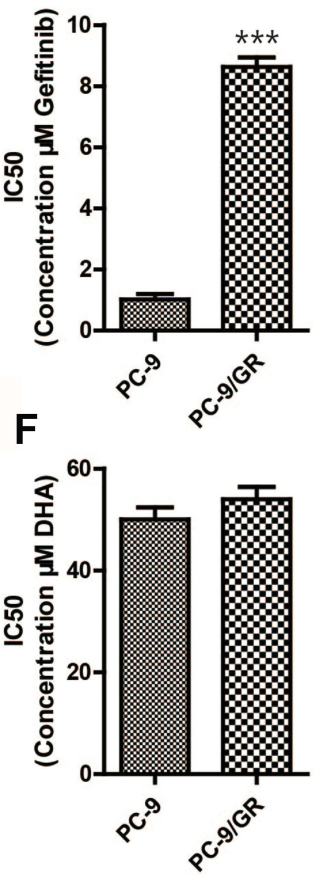

G PC-9

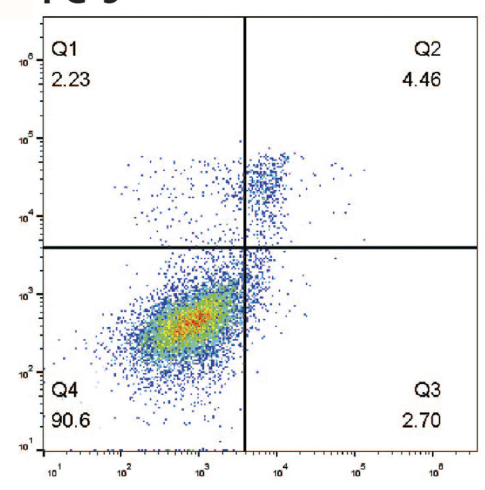

PC-9+DHA(50 $\mu \mathrm{M})$

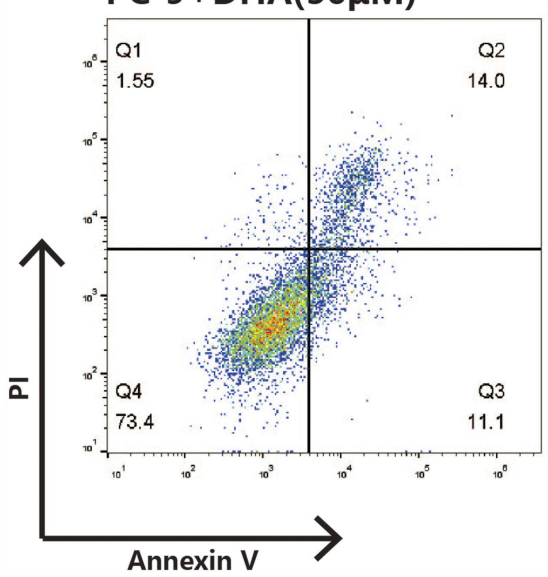

\section{PC-9/GR}

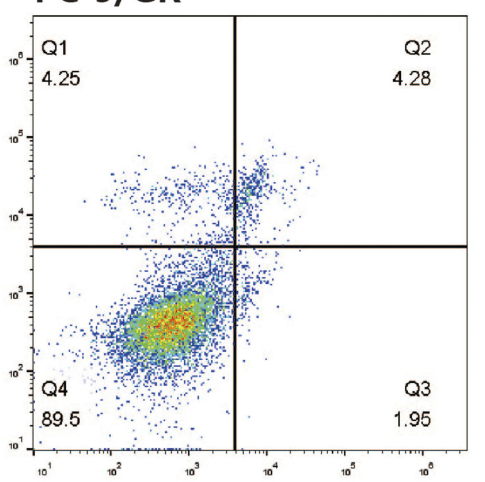

PC-9/GR+DHA(50 $\mu \mathrm{M})$

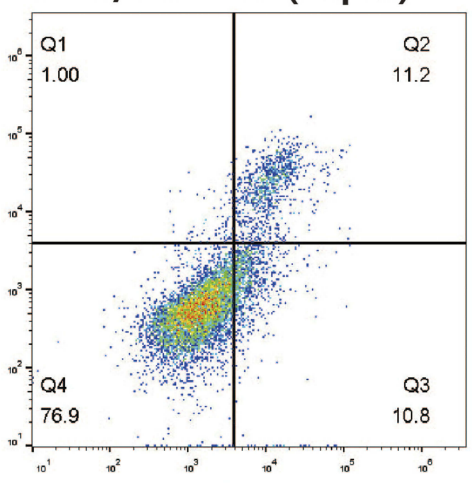

H

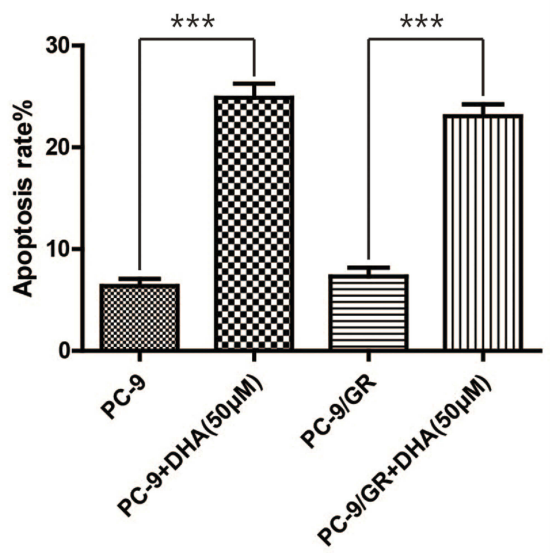

Figure I DHA induces apoptosis in PC-9 and PC-9/GR cells. (A-C) Inhibition rate of the two different cell lines (PC-9, PC-9/GR) was assessed after 24 hrs of gefitinib stimulation by CCK8 assay. (D-F) Inhibition rate of the two different cell lines (PC-9, PC-9/GR) was assessed after 24 hrs of DHA stimulation by CCK8 assay. (G-H) Both PC-9 and PC-9/GR cells were seeded in 6-well plates, after DHA (50 $\mu \mathrm{M})$ treatment for $24 \mathrm{hrs}$, both PC-9 and PC-9/GR cells were stained with Annexin V and PI and apoptosis cells were quantitated by flow cytometer. Results from the experiments are shown as means \pm SEM. The data are presented as the percentage of cell inhibition rate to unstimulated cells $(0 \mu \mathrm{M}) .{ }^{* * *} \mathrm{p}<0.00$ I versus non-treated control of $\mathrm{PC}-9$ and $\mathrm{PC}-9 / \mathrm{GR}$ cells. 
of DHA in PC-9 and PC-9/GR were almost the same. In comparison with PC-9 cells, the apoptotic rate of PC-9/GR differentiated inconspicuously after the treatment of DHA 50 $\mu \mathrm{M}$ for $24 \mathrm{hrs}$. These data demonstrated that DHA may play a suppressive role in the viability of NSCLC cells, namely, PC-9 and PC-9/GR, which contributed to the apoptosis in both cell lines. Moreover, there was no resistance of the PC9/GR cells to DHA, in contrast to Gefitinib.

\section{DHA Sensitized PC-9/GR Cell Lines To Gefitinib}

To identify whether DHA could be applied as a sensitizing agent for Gefitinib resistance, the combination of Gefitinib and $12.5 \mu \mathrm{M}, 25 \mu \mathrm{M}$ or $50 \mu \mathrm{M}$ DHA was treated with PC-9 and PC-9/GR cells. As displayed in Figure 2A-F, the IC50 of Gefitinib dramatically down-regulated both in PC-9 and in PC-9/GR cells after treating with $25 \mu \mathrm{M}$ and $50 \mu \mathrm{M}$ DHA. Subsequently, CI was calculated based on the data obtained from the CCK- 8 assay. The results suggested that the synergetic action has been found between DHA and Gefitinib when DHA was $25 \mu \mathrm{M}$. The apoptosis rate also remarkably elevated when PC-9 cells and PC-9/GR cells were incubated with DHA and Gefitinib, compared to the treatment of a single drug as revealed in Figure $2 \mathrm{G}-\mathrm{I}$. The above data demonstrated that the Gefitinib susceptibility in PC-9 cells could be enhanced by DHA, suggesting that DHA-induced inhibition of PC-9 viability might be regulated through the EGFR pathway. However, various differences between the results of the two tests were observed. The decline of Gefitinib IC50 was remarkable and the effective dose of Gefitinib for cell apoptosis combing with DHA nearly halved. It could be illustrated that under the synergistic effect of DHA, the PC-9/GR cell lines became more sensitive to Gefitinib. In order to evaluate the Gefitinib resistance revertant potentiality of DHA, a Gefitinib resistance formation model has been successfully established and applied in the present work. PC-9 was incubated with low-dose Gefitinib which increased with time. Simultaneously, DHA was added to another PC-9 group. It was shown in Figure 2J that the apoptosis rate accelerated and the Gefitinib tolerance of PC-9 increased after 6 months. The apoptosis rate of the group incubated with DHA was the highest, which was illustrated that the PC-9 cells in this group were still sensitive to Gefitinib, indicating that DHA could induce the Gefitinibresistant revertants. To verify the DHA-induced sensibilization to Gefitinib in vivo, we used PC-9 and PC-9/GR transplanted tumor model established in $\mathrm{BALB} / \mathrm{C}$ nude mice and the results agreed with the results in vito.

\section{DHA Enhanced The Absorption Of Chemotherapy Drugs}

Doxorubicin is a classic chemotherapy drug which took effects by interfering with the function of DNA. We performed the combination in which Gefitinib was replaced by doxorubicin to further identify the possible mechanisms of the increased Gefitinib susceptibility induced by DHA in PC-9/GR cell lines. The inhibition rate was detected when PC-9/GR cell lines were incubated combining doxorubicin with $12.5 \mu \mathrm{M}, 25$ $\mu \mathrm{M}$, or $50 \mu \mathrm{M}$ DHA. It was demonstrated in Figure 3A-E that the IC50 of doxorubicin in PC-9/GR cell lines was reduced, and the apoptosis rate accelerated. However, CI was higher than 1, manifesting that there was no synergistic effect between DHA and doxorubicin. Since doxorubicin had fluorescence activity, the drug absorption was evaluated by flow cytometry and it was revealed in Figure 3F-H that the absorption of doxorubicin enhanced. These results implied that DHA-mediated chemotherapy synergistic effect in PC-9/GR might not be mediated through the function of DNA. However, the enhanced drug absorption suggested that DHA may affect the functions of membrane proteins, like EGFR. Therefore, a fluorescent probe with Gefitinib quinazoline has been synthesized to evaluate the Gefitinib absorption synergized by DHA. The confocal images and fluorescence intensity assay based on flow cytometry collectively proved that with the help of DHA, Gefitinib sub-cellular localization and absorption increased as represented in Figure 3G-J.

\section{DHA Up-Regulated PC-9/GR Gefitinib Susceptibility Through The EGFR Pathway}

To further verify whether the DHA-mediated PC-9/GR chemotherapy synergistic effect was exerted via the EGFR pathway, we investigated the key protein expression of EGFR and its downstream signaling pathway. Figure $4 \mathrm{~A}$ and $\mathrm{B}$ demonstrated that there were no significant changes in EGFR phosphorylation or the downstream signaling PI3K/ Akt and MAPK/ERK in PC-9/GR cell lines when cells were incubated with Gefitinib alone. When DHA was added, the results indicated that the phosphorylation of EGFR and the downstream signaling PI3K/Akt and MAPK/ERK reduced. It was demonstrated that DHA-mediated improvement of Gefitinib susceptibility in PC-9/GR cell lines could be regulated through the EGFR pathway. Our previous study has proved that high levels of cholesterol in lipid rafts could reduce the sensitivity of EGFR-TKI treatment in non-small cell lung cancer. DHA, as a liposoluble compound, could replace the cholesterol in lipid rafts. Therefore, we speculated that it might 

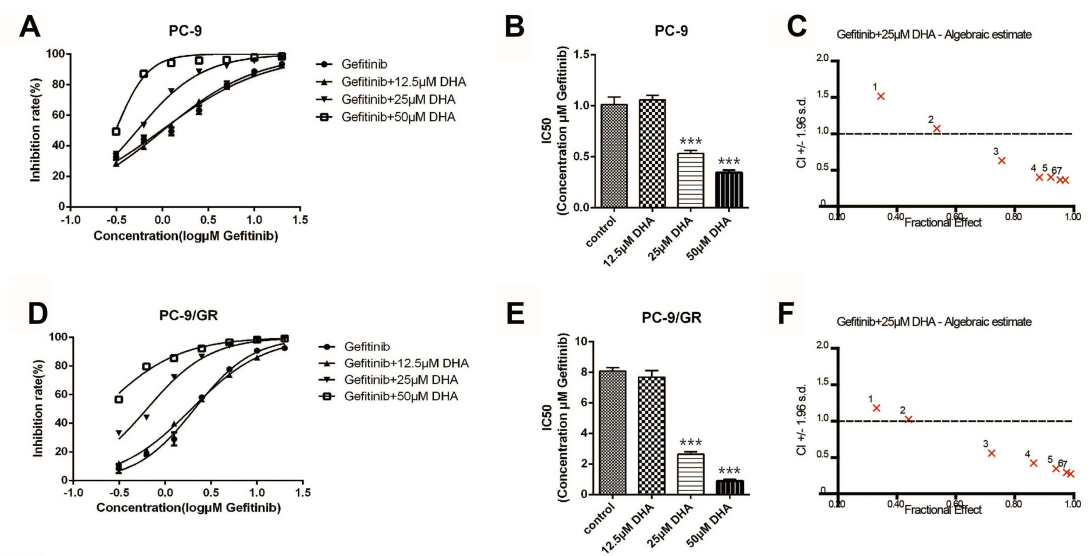

G

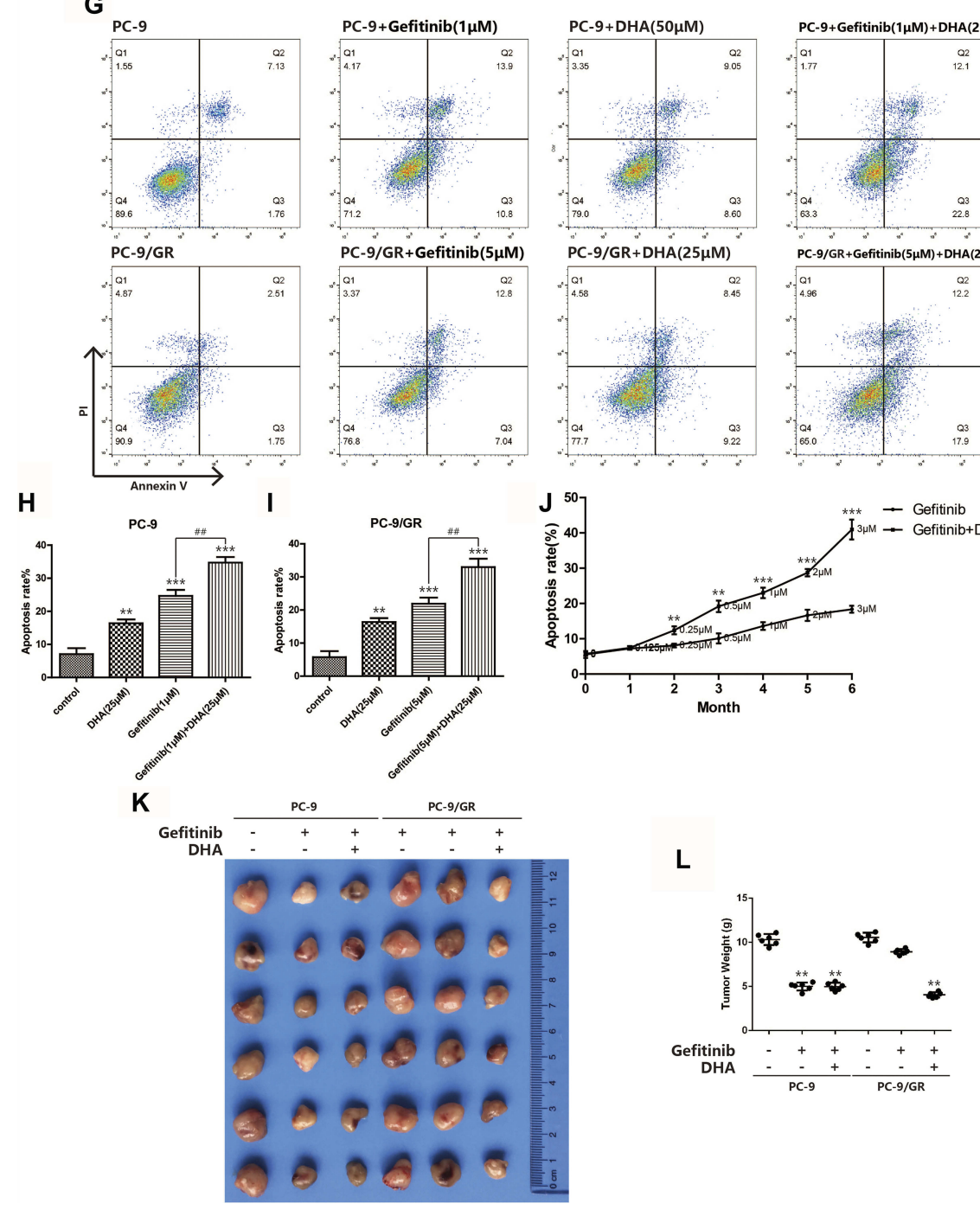

Figure 2 DHA sensitizes gefitinib-resistant cell line PC-9/GR to gefitinib. (A-B) Inhibition rate of PC-9 cells was assessed after $24 \mathrm{hrs}$ of stimulation of combination of gefitinib and DHA $(I 2.5 \mu \mathrm{M}, 25 \mu \mathrm{M}, 50 \mu \mathrm{M})$ by CCK 8 assay. Bars represent SEM, ${ }^{* * * *} \mathrm{p}<0.00$ I versus non-treated control of PC-9 cells. (C) Combination index was calculated by Calcusyn 2.0 based on the inhibition rate acquired in CCK8 assay. (D-E) Inhibition rate of PC-9/GR cells was assessed after $24 \mathrm{hrs}$ of stimulation of combination of gefitinib and DHA (I2.5 $\mu \mathrm{M}, 25 \mu \mathrm{M}, 50 \mu \mathrm{M})$ by CCK8 assay. Bars represent SEM, *** $\mathrm{P}<0.00 \mathrm{I}$ versus non-treated control of PC-9/GR cells. (F) Combination index was calculated by Calcusyn 2.0 based on the inhibition rate acquired in CCK8 assay. (G-I) PC-9 cells and PC-9/GR cells were stained with Annexin $V$ and PI and apoptosis cells were quantitated by flow cytometer after DHA ( $25 \mu \mathrm{M})$ and gefitinib (I $\mu \mathrm{M}, 5 \mu \mathrm{M})$ treatment. Results from the experiments are shown as means \pm SEM. The data are presented as the percentage of cell inhibition rate to unstimulated cells $(0 \mu M)$. Bars represent $S E M$, ${ }^{* *} \mathrm{p}<0.01$ or ${ }^{* * *} \mathrm{p}<0.001$ versus non-treated control of PC- 9 and PC-9/GR cells. ${ }^{2} \mathrm{p}<0.01$ versus non-DHA-treated of PC-9 and PC-9/GR cells. (J) Apoptosis rate of PC-9 cells was assessed after long-term gefitinib stimulation. The dosage of gefitinib was increased once a month for 6 months. DHA (I2.5 $\mu$ M) was added to another PC-9 group simultaneously. PC-9 cells were stained with Annexin $\mathrm{V}$ and $\mathrm{PI}$ and apoptosis cells were quantitated by flow cytometer. Bars represent SEM, ${ }^{* *} \mathrm{p}<0.0 \mathrm{I}$ or $* * * \mathrm{p}<0.00 \mathrm{I}$ versus non-DHA-treated of PC-9 cells. (K-L) PC-9 and PC-9/GR tumors were transplanted into BALB/C nude mice. Bars represent SEM, ${ }^{* *}$ p $<0.01$ versus non-treated control of PC-9 and PC-9/GR cells. 

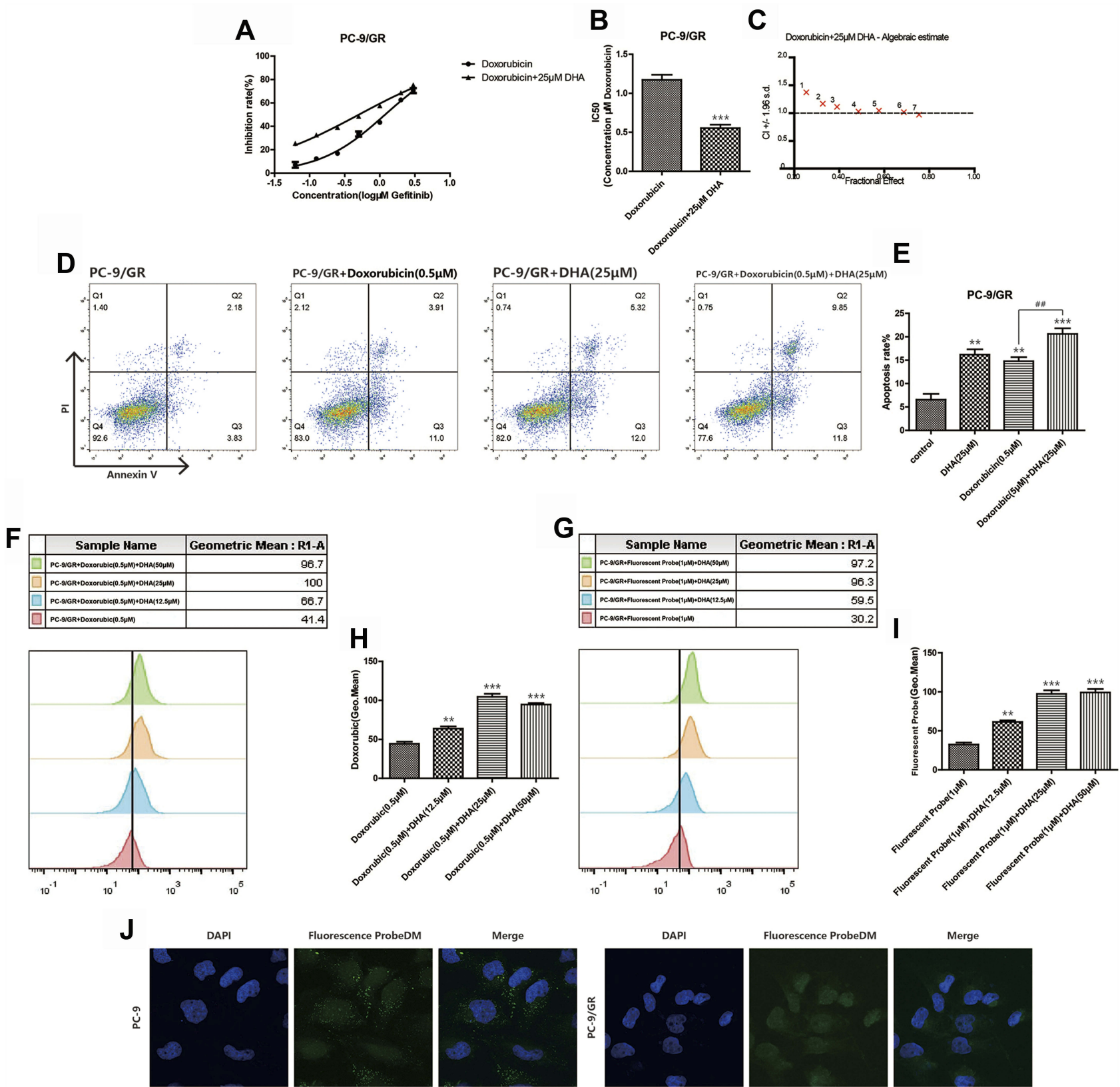

Fluorescence ProbeDM
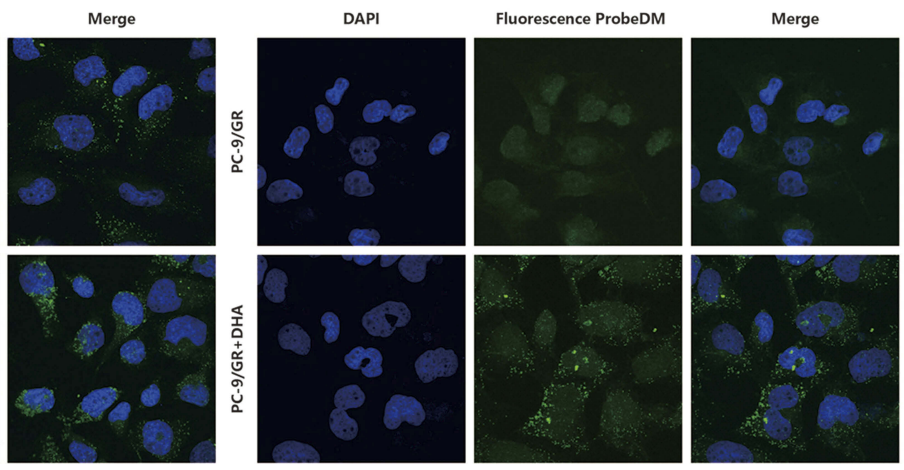

Figure 3 DHA increases chemotherapy drug absorption. (A-B) Inhibition rate of PC-9/GR cells was assessed after 24hrs of stimulation of combination of doxorubicin and DHA $(25 \mu \mathrm{M})$ by CCK8 assay. Bars represent SEM, $* * *$ p $<0.001$ versus non-treated control of PC-9/GR cells. (C) Combination index was calculated by Calcusyn 2.0 based on the inhibition rate acquired in CCK8 assay. (D-E) PC-9/GR cells were stained with Annexin $\mathrm{V}$ and PI and apoptosis cells were quantitated by flow cytometer after DHA $(25 \mu \mathrm{M})$ and doxorubicin $(0.5 \mu \mathrm{M})$ treatment. Results from the experiments are shown as means \pm SEM. The data are presented as the percentage of cell inhibition rate to unstimulated cells $(0 \mu \mathrm{M})$. Bars represent SEM, $* * 0<0.01$ or $* * * p<0.001$ versus non-treated control of PC-9 and PC-9/GR cells. $\#$ $\mathrm{p}<0.05$ versus non-DHA-treated of PC- 9 cells. $(\mathbf{F}-\mathbf{I})$ The fluorescence intensity was measured at 488-nm excitation and $575-\mathrm{nm}$ emission after cells were treated by doxorubicin and at $480-\mathrm{nm}$ excitation and $505-\mathrm{nm}$ emission after cells were treated by fluorescent probe using a fluorospectro photometer. Bars represent SEM, ** $<0.01$ or $* * * p<0.00$ I versus non-treated control of PC-9/GR cells. (J) PC-9 cells and PC-9/GR cells were incubated with the indicated concentration of DMSO, DHA $(25 \mu \mathrm{M})$ for $24 \mathrm{hrs}$ and then exposed for $3 \mathrm{hrs}$ to fluorescent probe with gefitinib skeleton ( $10 \mu \mathrm{mol} / \mathrm{L})$. Confocal images of cells show fluorescence of DAPI in blue, fluorescent probe in green, and are merged in Lane 3. 
A

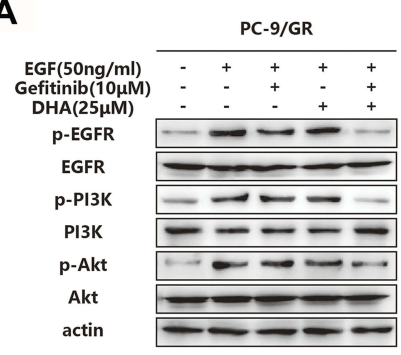

E

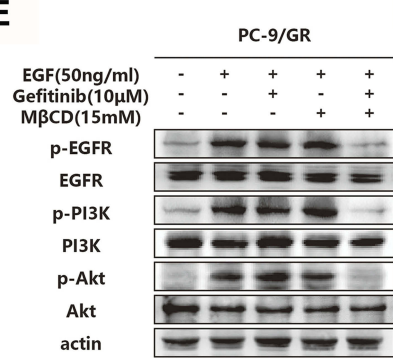

G

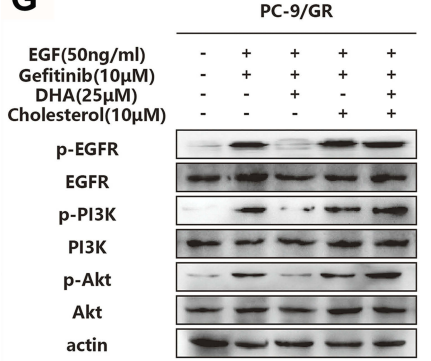

B

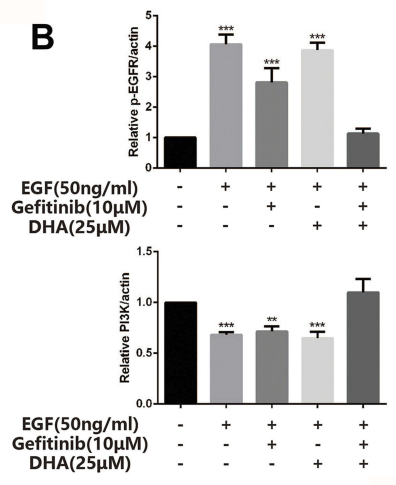

C

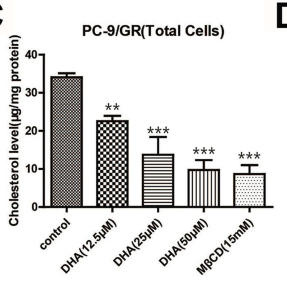

F

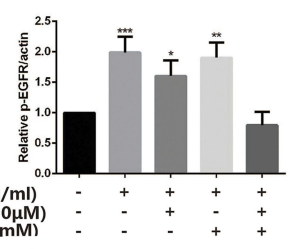

Gefitinib(100M)

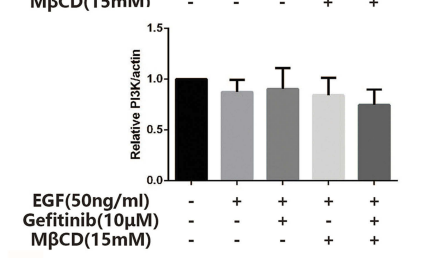

H

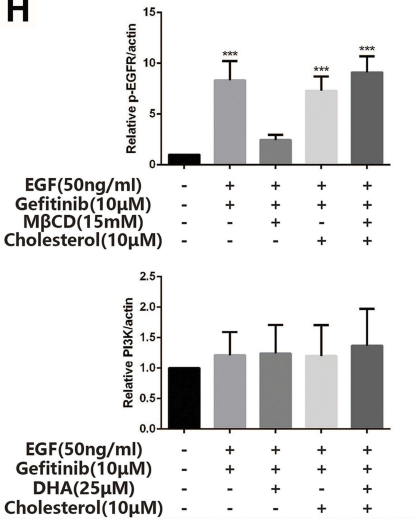

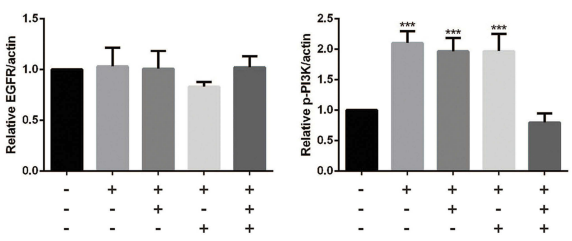

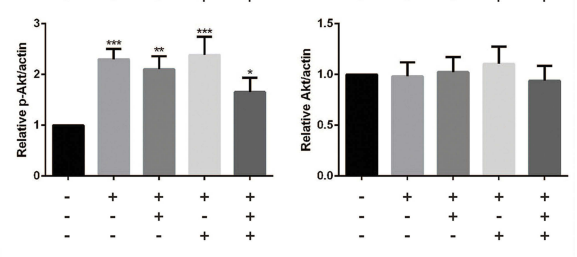

D

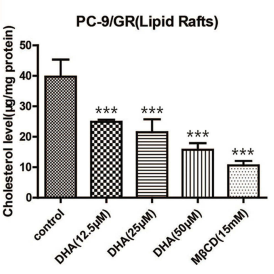

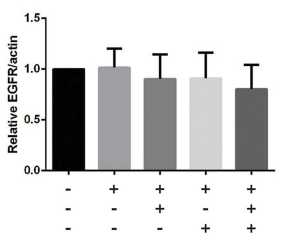
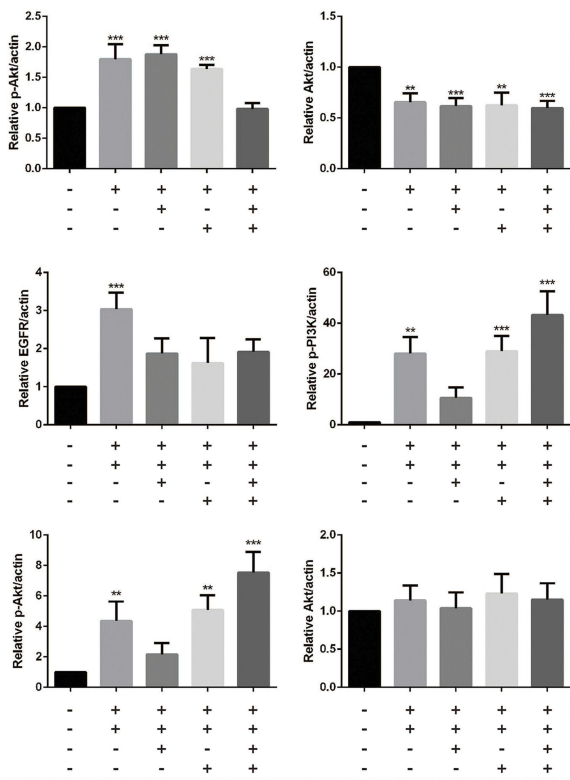
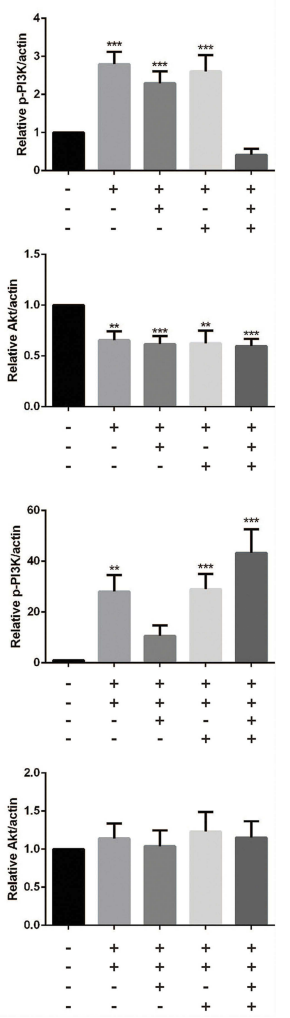

Figure 4 DHA increases PC-9/GR gefitinib susceptibility through EGFR pathway. (A-B) PC-9/GR cells were incubated with indicated concentration of gefitinib (I0 $\mu$ M), DHA $(25 \mu \mathrm{M})$ or combined treatment for $24 \mathrm{hrs}$. Before the collection of cell lysates and immunoblot analysis, cells were stimulated with $50 \mathrm{ng} / \mathrm{mL} E G F$ for 20 min at $37^{\circ} \mathrm{C}$. EGFR, PI3K, Akt and their phosphorylated protein expression were detected by Western blot as described. Bars represent SEM, *p<0.05, $* * p<0.0 \mathrm{I}$ or $* * * p<0.00 \mathrm{I}$ versus non-treated control of PC-9/GR cells. (C-D) Cholesterol was tested using the Amplex ${ }^{\circledR}$ Red Cholesterol Assay Kit. Absorbance was converted to $\mu \mathrm{g}$ cholesterol/mL utilizing a cholesterol standard curve, and then samples were normalized to protein concentration for a final value in $\mu \mathrm{g}$ cholesterol/mg protein. Lipid rafts were isolated from PC-9/GR cells as described in Experimental Procedure. Bars represent SEM, ${ }^{* *} \mathrm{p}<0.01$ or ${ }^{* * *} \mathrm{p}<0.00 \mathrm{I}$ versus non-treated control of PC-9/GR cells. (E-H) PC-9/GR cells were treated for $\mathrm{Ihr}$ with M $\mathrm{BCD}(15 \mathrm{mM})$ and then incubated in serum-free medium with or without cholesterol $(10 \mu \mathrm{M})$ for $2 \mathrm{hrs}$ at $37^{\circ} \mathrm{C}$. Before the collection of cell lysates and immunoblot analysis, cells were stimulated with $50 \mathrm{ng} / \mathrm{mL}$ EGF for $20 \mathrm{~min}$ at $37^{\circ} \mathrm{C}$. Then, Western blot was performed as described. Bars represent SEM, ${ }^{*} \mathrm{p}<0.05$, ${ }^{* *} \mathrm{p}<0.01$ or $* * * \mathrm{p}<0.001$ versus non-treated control of PC-9/GR cells.

be the displacement of cholesterol by DHA led to the increase of Gefitinib susceptibility. Afterwards, the cholesterol levels in PC-9/GR cell lines were analyzed, the results of which represented in Figure 4C and D that the decline of cholesterol was observed both in total cells and in lipid rafts after the DHA treatment. Since $\mathrm{M} \beta \mathrm{CD}$ contained the guest molecules, like 
cholesterol, it was applied to capture the cholesterol in lipid rafts. The results of Western blot analyses were consistent with that obtained from the DHA treatment. Additionally, after adding cholesterol in the medium, the sensitization of DHA for Gefitinib was shown to be invalid, as revealed in Figure 4E-H. The above data suggested that the synergistic effect and sensitization of DHA might be regulated through the displacement of cholesterol with DHA.

\section{DHA Sensitized PC-9 Cells To Gefitinib By Cholesterol Displacement}

For further verifying the relationship among Gefitinib sensibility, cholesterol and DHA, Western blot assay was adopted to investigate the phosphorylation of EGFR in PC-9 cells after the cholesterol and DHA treatment. As displayed in Figure $5 \mathrm{~A}$ and $\mathrm{B}$, the level of $\mathrm{p}$-EGFR was up-regulated by treating with cholesterol, which could be reduced by the DHA treatment. The CCK8 assay also proved that the IC50 of Gefitinib in PC-9 cell lines was up-regulated after the cholesterol treatment and then declined when DHA was added, revealing in Figure $5 \mathrm{C}$ and $\mathrm{D}$. The variations of apoptosis rate after treating with cholesterol and DHA also changed in a similar manner (Figure $5 \mathrm{E}$ and $\mathrm{F}$ ). The confocal images displayed that the drug absorption was also enhanced after the DHA treatment (Figure 5G). The above results suggested that the high level of cholesterol in lipid rafts played a role in the binding of EGFR-TKIs and its target to some extent. Besides, DHA could reduce the cholesterol in lipid rafts, inducing the binding of EGFR-TKIs and EGFR.

\section{Discussion}

In our study, DHA was found to play a role in suppressing the viability and inducing the apoptosis of PC-9/GR cell lines in vitro, probably through regulating EGFR and the downstream signaling pathway. DHA with the concentrations ranging from $10 \mu \mathrm{M}$ to $200 \mu \mathrm{M}$ has been applied to investigate the anti-tumor effects of DHA on colon, breast and prostate cancer cells. ${ }^{4}$ Consequently, a series of concentrations of DHA $(\leq 100 \mu \mathrm{M})$ were adopted in this work.

It has been reported that DHA had multiple anti-tumor effects, including inhibiting tumor angiogenesis, ${ }^{13}$ apoptosisinducing activity, ${ }^{14}$ suppressing tumor invasion and metastasis $^{15,16}$ and regulating signaling pathways. ${ }^{7}$ Beyond that, it has been proven that the levels of DHA in the serum of patients suffered from pancreatic cancer, lung cancer or nonHodgkin lymphoma were lower than those in normal controls. ${ }^{17}$ Furthermore, it has been published that the supplementation of EPA+DHA (2.5 g/day) to the NSCLC subjects under the platinum treatment led to a prominent enhancement of the rate of therapeutic response and positive clinical outcomes. ${ }^{9}$ Other clinical studies also demonstrated that DHA played a markedly protective role in protecting from lung cancer and high DHA intake was related to the lower risk of lung cancer. ${ }^{13,18}$ Since former researches have suggested that DHA was associated with cancer development, the present study demonstrated that DHA may contribute to revert the Gefitinib susceptibility which was correlated to the phosphorylation status of EGFR and the downstream signaling pathways in NSCLC cell lines.

As a transmembrane receptor tyrosine kinase, the overexpressed EGFR has been broadly discovered in NSCLC. ${ }^{19}$ The downstream signaling pathways participated in the mediation of tumor growth, invasion and metastasis could be stimulated by the activated EGFR. ${ }^{20}$ Incorporating onto the membranes, DHA played a role in regulating the functions of cellular membranes and the organization of lipid rafts, displacing EGFR from lipid rafts, which subsequently resulted in the suppression of the downstream signaling activities. ${ }^{21,22}$ Our research suggested that the Gefitinib susceptibility in both PC9 and PC-9/GR cell lines was increased after treating with DHA. The results of CI revealed that DHA acted synergistically with Gefitinib rather than doxorubicin, indicating that DHA-mediated chemotherapy susceptibility might be upregulated through the EGFR signaling pathway. Besides, immunofluorescence and flow cytometry were applied to identify the absorption, subcellular distribution of the fluorescent probe similar to Gefitinib, which revealed that DHA remarkably enhanced the affinity of the fluorescent probe and EGFR. Additionally, it was demonstrated that DHA may play a therapeutic role by changing the phosphorylation status of EGFR and the downstream signaling pathways in PC-9/GR cell lines.

As a widely studied cell death pathway in literature, apoptosis was found to be significantly related to EGFR and its downstream signaling pathways. ${ }^{23,24}$ Clinical researches have proved that the resistance was inevitable after the long-term EGFR-TKI treatment. ${ }^{25,26}$ Consequently, the formation of Gefitinib resistance was stimulated by the continuous administration of low-dose Gefitinib. During this period, the dose of Gefitinib was increased every other month and the apoptosis rate was analyzed to evaluate the Gefitinib tolerance. Our results of Annexin V/PI staining assay illustrated that there was no increase in the tolerance of Gefitinib after the DHA treatment, indicating that DHA might delay the process of drug resistance, or even revert the Gefitinib resistance. 
A

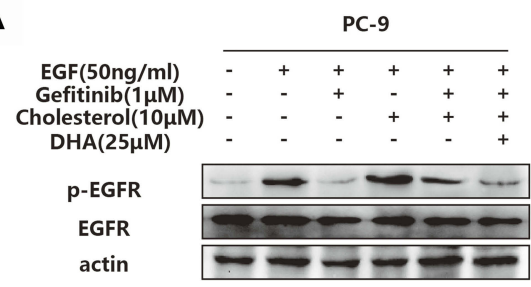

C

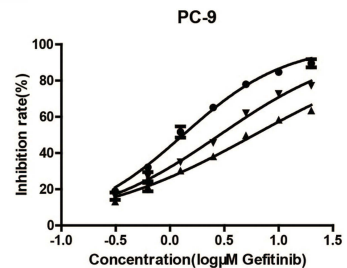

B

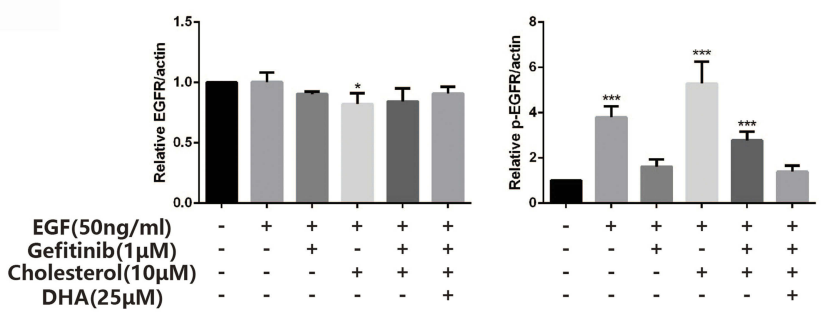

D
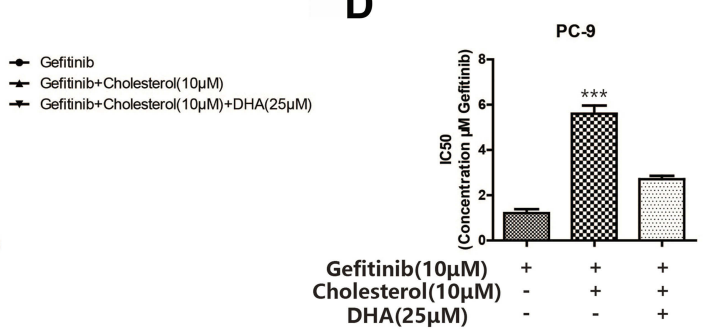

E

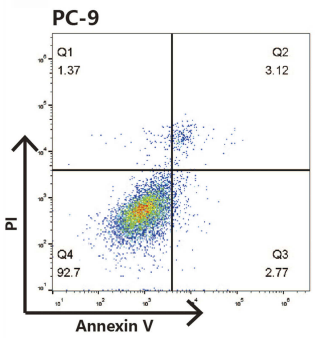

PC-9+Cholesterol $(10 \mu \mathrm{M})$
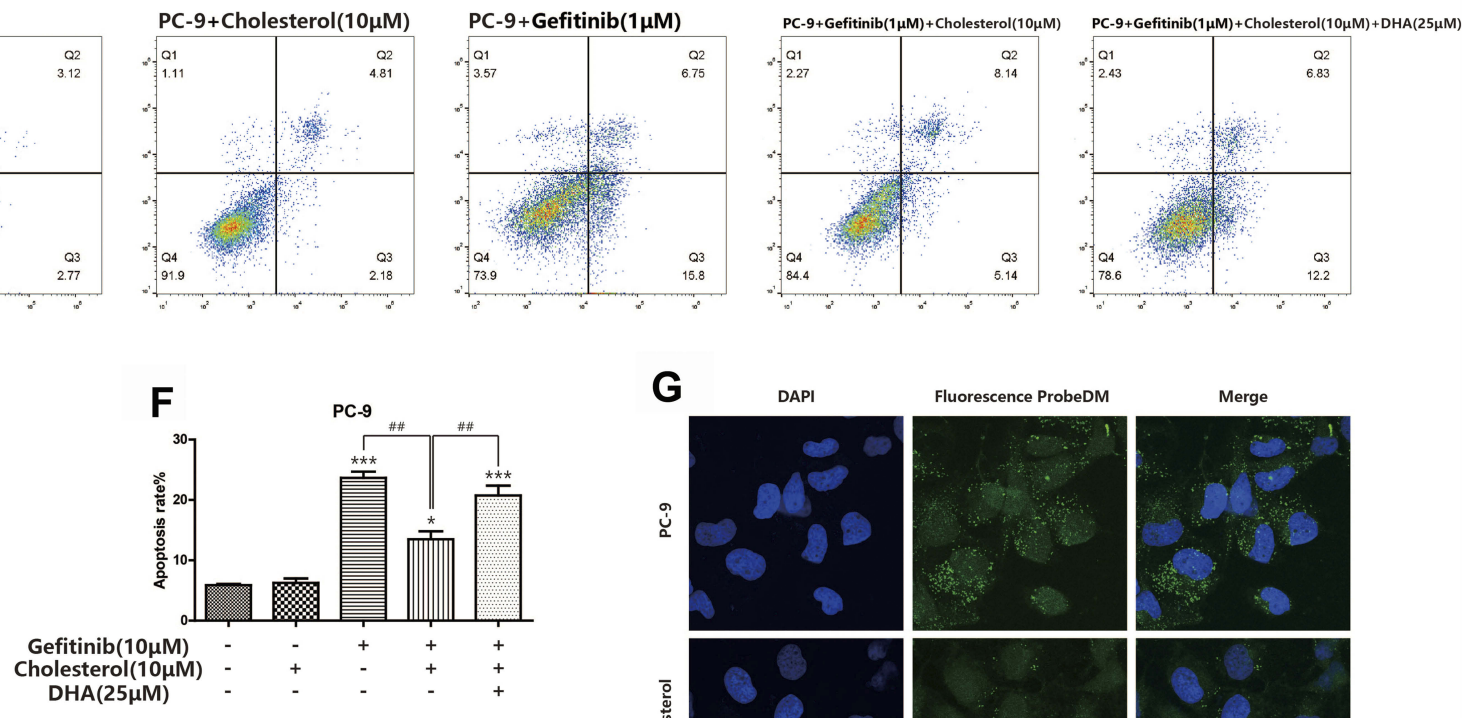

G
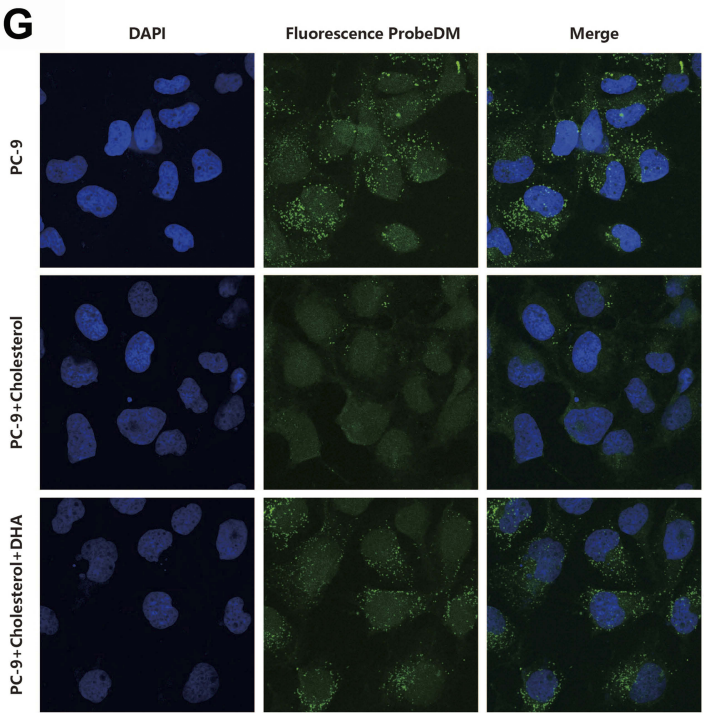

Figure 5 DHA sensitizes PC- 9 cells to gefitinib by cholesterol displacement. (A-B) PC- 9 cells were incubated in serum-free medium with or without cholesterol (I $\mu$ M) for $2 \mathrm{hrs}$ at $37^{\circ} \mathrm{C}$. Then, PC-9 cells were incubated with the indicated concentration of gefitinib $(1 \mu \mathrm{M})$, DHA $(25 \mu \mathrm{M})$ or combined treatment for $24 \mathrm{hrs}$. Before the collection of cell lysates and immunoblot analysis, cells were stimulated with $50 \mathrm{ng} / \mathrm{mL}$ EGF for 20 min at $37^{\circ} \mathrm{C}$. EGFR, and its phosphorylated protein expression were detected by Western blot as described. Bars represent SEM, ${ }^{*} \mathrm{p}<0.05$, ${ }^{* * *} \mathrm{p}<0.00$ I versus non-treated control of PC-9 cells. (C-D) Inhibition rate of PC-9 cells was assessed after $24 \mathrm{hrs}$ of stimulation of combination of gefitinib, cholesterol $(\mathrm{I} 0 \mu \mathrm{M})$ and DHA $(25 \mu \mathrm{M})$ by CCK 8 assay. Bars represent SEM, *** $<<0.00 \mathrm{I}$ versus non-treated control of PC-9 cells. (E-F) PC-9 cells were stained with Annexin $\mathrm{V}$ and PI and apoptosis cells were quantitated by flow cytometer after cholesterol (IO $\mu \mathrm{M}$ ), DHA $(25 \mu \mathrm{M})$ and gefitinib $(I \mu \mathrm{M})$ treatment or combined treatment as described above. Results from the experiments are shown as means \pm SEM. The data are presented as the percentage of cell inhibition rate to unstimulated cells $(0 \mu \mathrm{M})$. Bars represent SEM, ${ }^{*} p<0.05$, ${ }^{* * *} p<0.00$ I versus non-treated control of PC-9 cells. ${ }^{\# \#} \mathrm{p}<0.0 \mathrm{I}$ versus non-DHA-treated of PC-9 cells. (G) PC-9 cells were incubated with indicated concentration of DMSO, DHA ( $25 \mu \mathrm{M})$ for $24 \mathrm{hrs}$, cholesterol (I0 $\mu$ M), then exposed for $3 \mathrm{hrs}$ to fluorescent probe with gefitinib skeleton $(10 \mu \mathrm{mol} / \mathrm{L})$. Confocal images of cells show fluorescence of DAPI in blue, fluorescent probe in green, and are merged in Lane 3. 
Herein, we demonstrated that the integrated treatment of DHA and Gefitinib in PC-9 and PC-9/GR cell lines played a greater inhibitory role in EGFR phosphorylation and its downstream kinase of EGFR pathway, in comparison with the cells only treated with Gefitinib. The suppression might contribute to improve susceptibility and revert the resistance of Gefitinib in vitro. Nevertheless, further studies are urgently needed to identify the mechanism through which DHA mediates its effect on EGFR. Our work also warrants the following clinical researches to investigate the application of DHA as a novel and promising agent of clinical interest in the therapy of NSCLC patients.

\section{Acknowledgments}

This project was supported by the National Science Foundation for Young Scientists of China (Grant No. 81803565), and Basic Foundation for China Pharmaceutical Universities (Grant No. 2632018PY03).

\section{Disclosure}

The authors report no conflicts of interest in this work.

\section{References}

1. Pinsky PF. Lung cancer screening with low-dose CT: a world-wide view. Transl Lung Cancer Res. 2018;7(3):234-242. doi:10.21037/tlcr.201 8.05.12

2. Aguilar KM, Winfree KB, Muehlenbein CE, et al. Treatment patterns by EGFR mutation status in non-small cell lung cancer patients in the USA a retrospective database analysis. Adv Ther. 2018;35(11):1905-1919. doi:10.1007/s12325-018-0811-0

3. Wang J, Zhu M, Wang L, Chen C, Song Y. Amphiregulin potentiates airway inflammation and mucus hypersecretion induced by urban particulate matter via the EGFR-PI3Kalpha-AKT/ERK pathway. Cell Signal. 2019;53:122-131. doi:10.1016/j.cellsig.2018.10.002

4. Tasaki S, Horiguchi A, Asano T, Ito K, Asano T, Asakura H. Docosahexaenoic acid inhibits the phosphorylation of STAT3 and the growth and invasion of renal cancer cells. Exp Ther Med. 2017;14 (2):1146-1152. doi:10.3892/etm.2017.4616

5. Pizato N, Luzete BC, Kiffer L, et al. Omega-3 docosahexaenoic acid induces pyroptosis cell death in triple-negative breast cancer cells. Sci Rep. 2018;8(1):1952. doi:10.1038/s41598-018-20422-0

6. Corsetto PA, Colombo I, Kopecka J, Rizzo AM, Riganti C. Omega-3 long chain polyunsaturated fatty acids as sensitizing agents and multidrug resistance revertants in cancer therapy. Int J Mol Sci. 2017;18:12. doi:10.3390/ijms 18122770

7. Morin C, Fortin S. Docosahexaenoic acid monoglyceride increases carboplatin activity in lung cancer models by targeting EGFR. Anticancer Res. 2017;37(11):6015-6023. doi:10.21873/anticanres.12048

8. de Aguiar Pastore Silva J, Emilia de Souza Fabre M, Waitzberg DL. Omega-3 supplements for patients in chemotherapy and/or radiotherapy: a systematic review. Clin Nutr. 2015;34(3):359-366. doi:10.1016/j. clnu.2014.11.005

9. Murphy RA, Mourtzakis M, Chu QS, Baracos VE, Reiman T, Mazurak VC. Nutritional intervention with fish oil provides a benefit over standard of care for weight and skeletal muscle mass in patients with nonsmall cell lung cancer receiving chemotherapy. Cancer. 2011;117(8):1775-1782. doi:10.1002/cncr.25709
10. Bougnoux P, Hajjaji N, Ferrasson MN, Giraudeau B, Couet C, Le Floch O. Improving outcome of chemotherapy of metastatic breast cancer by docosahexaenoic acid: a phase II trial. $\mathrm{Br} J$ Cancer. 2009;101(12):1978-1985. doi:10.1038/sj.bjc.6605441

11. Chou TC. Theoretical basis, experimental design, and computerized simulation of synergism and antagonism in drug combination studies. Pharmacol Rev. 2006;58(3):621-681. doi:10.1124/pr.58.3.10

12. Newell M, Goruk S, Mazurak V, Postovit L, Field CJ. Role of docosahexaenoic acid in enhancement of docetaxel action in patient-derived breast cancer xenografts. Breast Cancer Res Treat. 2019;177(2):357-367. doi:10.1007/s10549-019-05331-8

13. van der Meij BS, Langius JA, Spreeuwenberg MD, et al. Oral nutritional supplements containing n-3 polyunsaturated fatty acids affect quality of life and functional status in lung cancer patients during multimodality treatment: an RCT. Eur J Clin Nutr. 2012;66 (3):399-404. doi:10.1038/ejcn.2011.214

14. Geng L, Zhou W, Liu B, Wang X, Chen B. DHA induces apoptosis of human malignant breast cancer tissues by the TLR-4/PPAR-alpha pathways. Oncol Lett. 2018;15(3):2967-2977. doi:10.3892/ol.2017.7702

15. Rahman MM, Veigas JM, Williams PJ, Fernandes G. DHA is a more potent inhibitor of breast cancer metastasis to bone and related osteolysis than EPA. Breast Cancer Res Treat. 2013;141 (3):341-352. doi:10.1007/s10549-013-2703-y

16. Hwang JK, Yu HN, Noh EM, et al. DHA blocks TPA-induced cell invasion by inhibiting MMP-9 expression via suppression of the PPAR-gamma/NF-kappaB pathway in MCF-7 cells. Oncol Lett. 2017;13(1):243-249. doi:10.3892/ol.2016.5382

17. Cvetkovic Z, Vucic V, Cvetkovic B, et al. Abnormal fatty acid distribution of the serum phospholipids of patients with non-Hodgkin lymphoma. Ann Hematol. 2010;89(8):775-782. doi:10.1007/s00277-010-0904-6

18. Gleissman H, Johnsen JI, Kogner P. Omega-3 fatty acids in cancer, the protectors of good and the killers of evil? Exp Cell Res. 2010;316 (8):1365-1373. doi:10.1016/j.yexcr.2010.02.039

19. Tanaka H, Sakagami H, Kaneko N, et al. Mutant-selective irreversible EGFR inhibitor, naquotinib, inhibits tumor growth in NSCLC models with EGFR activating mutations, T790M mutation and AXL overexpression. Mol Cancer Ther. 2019;18:1366-1373. doi:10.1158/ 1535-7163.MCT-18-0976

20. Hou X, Du H, Quan X, et al. Silibinin inhibits NSCLC metastasis by targeting the EGFR/LOX pathway. Front Pharmacol. 2018;9:21. doi:10.3389/fphar.2018.00021

21. Langelier B, Linard A, Bordat C, Lavialle M, Heberden C. Long chain-polyunsaturated fatty acids modulate membrane phospholipid composition and protein localization in lipid rafts of neural stem cell cultures. J Cell Biochem. 2010;110(6):1356-1364. doi:10.1002/ jcb. 22652

22. Chen Q, Pan Z, Zhao M, et al. High cholesterol in lipid rafts reduces the sensitivity to EGFR-TKI therapy in non-small cell lung cancer. J Cell Physiol. 2018;233(9):6722-6732. doi:10.1002/jcp.26351

23. Ohm AM, Affandi T, Reyland ME. EGF receptor and PKCdelta kinase activate DNA damage-induced pro-survival and pro-apoptotic signaling via biphasic activation of ERK and MSK1 kinases. J Biol Chem. 2019;294(12):4488-4497. doi:10.1074/jbc. RA118.006944

24. Xia X, Liu Y, Liao Y, et al. Synergistic effects of gefitinib and thalidomide treatment on EGFR-TKI-sensitive and -resistant NSCLC. Eur J Pharmacol. 2019;856:172409. doi:10.1016/j.ejphar.2019.172409

25. Yang F, Qin Y, Wang Y, et al. Metformin inhibits the NLRP3 inflammasome via AMPK/mTOR-dependent effects in diabetic cardiomyopathy. Int J Biol Sci. 2019;15(5):1010-1019. doi:10.7150/ ijbs. 29680

26. Akamatsu H, Koh Y, Ozawa Y, et al. Osimertinib with ramucirumab in EGFR-mutated, T790M-positive patients with progression during EGFR-TKI therapy: phase Ib study. Clin Lung Cancer. 2018;19(6): e871-e874. doi:10.1016/j.cllc.2018.08.001 


\section{Publish your work in this journal}

OncoTargets and Therapy is an international, peer-reviewed, open access journal focusing on the pathological basis of all cancers, potential targets for therapy and treatment protocols employed to improve the management of cancer patients. The journal also focuses on the impact of management programs and new therapeutic agents and protocols on patient perspectives such as quality of life, adherence and satisfaction. The manuscript management system is completely online and includes a very quick and fair peer-review system, which is all easy to use. Visit http://www.dovepress.com/ testimonials.php to read real quotes from published authors.

Submit your manuscript here: https://www.dovepress.com/oncotargets-and-therapy-journal 